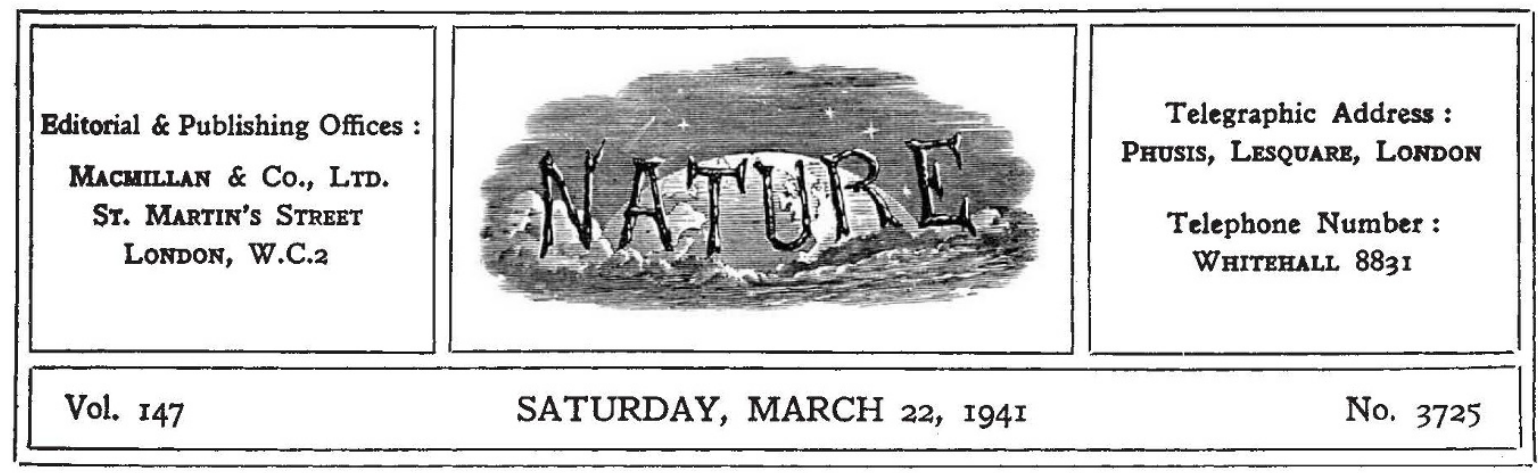

\title{
FOOD DISTRIBUTION IN WAR-TIME
}

$\mathrm{T}$ HE food policy of the Government during the present War has followed three main lines: it has provided for the accumulation of stocks of certain essential commodities against siege conditions; it has largely prevented profiteering and has achieved a reasonably equitable distribution of food by a system of rationing, by price control and by subsidizing the consumption of certain foodstuffs; it has also, by special subsidies, as in the case of milk, and by a system of differential prices in the case of margarine, done much to ensure the adequate nutrition of the poorer groups of consumers. It is indeed probable that during the first year of war, with the increase in employment and earnings, and with little diminution in the supply of food, the general average of nutrition was as high, if not higher, than in peace. Recently, however, the position has altered, and it is doubtful if the policy which was successful in 1940 will be adequate for 1941 .

The increase in sinkings which occurred in the last quarter of 1940 , and the additional calls on shipping resulting from the African campaign, has entailed a revision of the food import programme. "Beef or Bardia" still holds. In consequence, we cannot expect in 1941 to live as comfortably or to eat the same kind of food as we ate in 1940 or before the War. It will be necessary to change our dietary habits, to depend less on meat and more on cereals, potatoes and the cheaper vegetable foods. But if available shipping is directed to the importation of essential foodstuffs, if each prospective cargo is considered in terms of the national health, we shall have enough to eat and remain a fit nation at the end of the War.

The matter, however, does not end with the question of maintaining supplies. The question of distribution is equally important. There must be no unfair distribution of food between income classes. As the food situation deteriorates, unrationed foods increase in importance. When scarce supplementary foods are neither controlled in price nor officially rationed, they will be mainly consumed by those who can afford to buy them There will be no queues, but the lower income groups will go without. Poultry and canned fruit, for example, provide welcome additions to the diet of the well-to-do, but are little eaten by the poor. Restaurant meals are expensive and are mainly eaten by the rich.

In addition to the difficulty of distribution which inevitably arises in case of shortage, the 'blitz' has introduced problems of its own. When the bombing of London was at its height, too many young men and women, after spending an uncomfortable and exhausting night in a shelter remote from their homes, began their day's work on rolls and coffee because they could not afford a satisfactory breakfast. This condition, if allowed to persist, is likely to have a harmful effect on health and to hinder the national effort.

The problem of food distribution, therefore, resolves itself into ensuring that available supplies are spread over the population in accordance with needs, that the lower income groups get their fair share, and that adequate facilities are provided for feeding elements of the population whose nutrition is likely to suffer as a result of war conditions. Inequalities in distribution, which might be overlooked if other foods were plentiful, become important in a period of general scarcity, and the time appears to have arrived for a revision of the rationing system.

This revision might take one of several forms 
It might be accomplished by introducing the point system, used in Germany, in which each person is given a weekly number of points which are evaluated in terms of different foods. Such a system has, however, the disadvantage that it is highly complicated in operation, and leaves the retailer too much discretion in deciding the food value of different qualities of the same commodity.

Alternatively, a limit could be placed on the weekly per capita expenditure on food. The objection to this method is that its adoption might result in the rich competing with the poor for the cheaper foods. This objection has been considered invalid on the ground that, if the rich did compete for the cheaper foods, the more expensive foods would fall in price and would be available to the poor. It is, however, doubtful if this would happen. In the case of certain foods it is more likely that they would go off the market. In the case of others it is likely that the present differential in price, which occurs between, say, high-price and low-price cuts of meat, would disappear, and that the poor would pay rather more for their meat and the rich less.

On balance, it appears probable that the extension of the present system of rationing to essential commodities in short supply is likely to prove more satisfactory than a system of general rationing. In cases where the amount of a commodity to be distributed is small and unlikely to provide an adequate national ration, the introduction of alternative rations might be considered. Eggs or cheese, for example, might be purchased on the same coupon. Also the rationing system should be as flexible as possible in order to admit full advantage being taken of foods which were temporarily plentiful.

It is, however, highly desirable that rationing should be supported by an extension of the present system of providing subsidies for special classes of consumers. The milk scheme which, at certain levels of income, enables free milk to be distributed to nursing and expectant mothers and to children under five, and which provides milk at a reduced price to the same classes, and to school children, whatever the income, is an important step in social progress. The classes to which it applies could, however, be widened in dealing with the distribution of certain foodstuffs.

During war the effect of rising prices is most severely felt by families with more than three children and by the small fixed-income groups, that is, by old-age pensioners, by pensioned widows and orphans, by the unemployed, by the families of men in the Services, and by persons in receipt of public assistance.

These, together with the present beneficiaries under the cheap milk scheme, and families with more than three children, form a substantial part of the population, and are likely to suffer hardship as a result of war. It is therefore suggested that certain foodstuffs in plentiful supply might be provided by subsidy to these classes.

In practice, the subsidy might operate by permitting the purchase of a daily per capita allowance of specific foodstuffs at a reduced price. It could apply in the first instance to such things as potatoes, which, compared with bread on a calorie basis, are expensive, to carrots and to green vegetables. It might also be applied to jam, which plays an important part in the dietary of the poor.

The adequate nutrition of the population in war-time, as well as the equitable distribution of food, would also be assisted by providing facilities for communal or collective feeding. Already a certain amount of work has been done in supplying meals in shelters, while the Ministry of Labour and National Service has been given powers to compel the owner of a factory engaged in Government contracts, and employing more than 250 workers, to provide a work's canteen. The efforts have, however, been largely unco-ordinated and spasmodic, and a more systematic approach to the problem is required.

Apart from the obvious economies which would be effected in the cost of materials, and in labour, equipment and fuel, the communal meal enables the right kind of food to be fed to different classes of workers. It makes possible the addition in concentrated form of essential food constituents not present in the original foods.

The provision of communal restaurants near large shelters would have a beneficial effect on the health of the shelter population, while the provision of works' canteens under proper supervision would do much to ensure the adequate nutrition of the factory worker, a problem which will increase in importance as more married women are employed in industry. In the same way, a midday meal in schools would help to safeguard the health of the future generation.

It is doubtful, however, whether any scheme will develop with sufficient speed unless it obtains the more active support of the Government. This support would be most adequately given in two directions: (1) by prescribing minimum 
standards to be applied to collective feeding and by enforcing these standards by a competent inspectorate; (2) by training and registering staff for new canteens. The scheme might be operated partly by paid and partly by voluntary labour, and organized on a regional basis, linked up with the existing regional organizations. It would then, besides providing an immediate service, be available to undertake emergency feeding in any particular area.

\section{PREHISTORIC COMMUNITIES OF THE BRITISH ISLES}

Prehistoric Communities of the British Isles By Prof. V. Gordon Childe. Pp. xiv $+274+16$ plates. (London and Edinburgh: W. \& R. Chambers, Ltd., 1940). 20s. net.

THE study of our prehistoric antiquities has 1 already passed through several phases. The early antiquaries of Tudor and Stuart times are perhaps the most to be envied, for they could travel the country and indulge in picturesque speculation on what they saw, untrammelled by any established body of knowledge. The later eighteenth and nineteenth centuries witnessed the development of excavation, excavation which, while it began to accumulate the factual material necessary for later scientific study, was too often little more than looting to satisfy the collector's instinct and the land-owner's vanity and curiosity. By the beginning of the present century a rickety framework of information had been put together, and the achievement of outstanding individuals such as General Pitt-Rivers already gave promise of the extraordinary blossoming of a truly scientific archæology which took place in the period between two wars. The greater part of this happy period was naturally occupied with the essential preliminary task of extending conventional history backwards by establishing a fixed chronology, tracing invasions, the development of cultures and their interactions. But latterly a new trend was evident. Excavation had become sufficiently widespread, exact and selective to enable some archæologists to be less purely historical and more generally sociological in their approach. Attention began to be focused on the manner of prehistoric life, the structure of early societies, their economic basis and the density of their populations.

Prof. Childe looks through a historian's eyes, but he is far too sensitive to contemporary influence to ignore the new opportunities that were ready to his hand. Hence in this book he undertakes the difficult task of running the two methods, the historical and the sociological, in double harness. The plan of the whole book is historical : after a quick sketch of the first emergence of human societies in Palæolithic times, he follows their evolution in Britain down to the Roman period, with all the tale of invasions and cultural influences and the full archæological panoply of pot- and tool-typology. By dividing the space of time covered by the Neolithic, Bronze and Iron ages into nine parts, he even provides the first modern period-scheme for Great Britain comparable with the classic chronologies of Montelius, Muller and others on the Continent. Yet, throughout, social and economic changes are kept well to the fore, so that the book can with justice claim to be the first "to present a comprehensive account of the development of the societies inhabiting the British Isles in prehistoric times", and it is this aspect which is most stimulating and original.

The adoption of a "neolithic" economy, with agriculture and stock-breeding in place of hunting and food-gathering, must always cause an increase in population, and this fact, together with the soil exhaustion due to primitive agricultural methods, necessitates continual expansion on to new land. It was largely by this means that neolithic culture spread slowly westward from its eastern cradle until at last it reached our shores. Once arrived, this same economic urge dispersed it rapidly over the lighter soils of Britain, wherever simple hoe agriculture could be practised and flocks find open grazing. Prof. Childe makes the interesting point that one among the several distinguishable groups of neolithic settlers, the bearers of the Boyne culture, represent a rather different economy, the line of their settlement being dictated more by considerations of trade in gold and other metals than by those of husbandry. Although neolithic communities were very largely self-sufficing, there was one specialized industry of some importance-the mining of flint and extensive trading of axes made from it--which must have been in professional hands.

Side by side with the full neolithic societies there persisted a rather more primitive native culture which, although it had adopted certain neolithic traits such as potting, was still mainly dependent on the old food-gathering methods, and this element was to re-emerge in the Bronze Age, when for a time the relative importance of agriculture declined. 